\title{
Production of Arachidonic Acid and Eicosapentaenoic Acid by Mortierella alpina CBS 528.72 on Date Waste
}

\author{
Seyedeh Zeinab Asadi', \\ Kianoush Khosravi-Darani2*, \\ Houshang Nikoopour ${ }^{1}$ \\ and Hossein Bakhoda ${ }^{3}$
}

'Department of Food Science and Technology, Science and Research Branch, Islamic Azad University, Tehran, Iran

${ }^{2}$ Department of Food Technology Research, National Nutrition and Food Technology Research Institute, Faculty of Nutrition Sciences and Food Technology, Shahid Beheshti University of Medical Sciences, Tehran, Iran

${ }^{3}$ Department of Agricultural Mechanization, Science and Research Branch, Islamic Azad University, Tehran, Iran

Received: 9 June 2017 Accepted: 15 February 2018

\author{
*Corresponding author: \\ Phone: +982122086348; \\ Fax: +982122376473; \\ E-mail:k.khosravi@sbmu.ac.ir, \\ kiankh@yahoo.com \\ ORCID ID: 0000-0002-0269-6385 \\ (Khosravi-Darani)
}

\begin{abstract}
SUMMARY
Arachidonic acid (ARA) and eicosapentaenoic acid (EPA) are important for human health and are produced by the fungus Mortierella alpina. Fermentation conditions may affect fatty acid profile of produced oil. Substrates in solid-state fermentation are usually renewable and low-cost agro-industrial waste. The aim of this research is to study simultaneous production of ARA and EPA by M. alpina CBS 528.72 in solid-state fermentation. Date waste and soybean meal served as carbon and nitrogen sources, respectively. Plackett-Burman design was used to evaluate the impact of eleven process variables on ARA and EPA production. Analysis of the results showed that the main variables with significant impact on production include seed age, and supplementation of linseed oil and nitrogen. These three variables were then studied in a central composite design for the optimization of production of both fatty acids. Finally, reconfirmation test was conducted to obtain experimental results from predicted optimum conditions. This report showed that simultaneous optimization of the production of ARA and EPA by M. alpina CBS 528.72 on date waste can be achieved by modification of process variables in solid-state fermentation.
\end{abstract}

Key words: arachidonic acid (ARA), date waste, experimental design, eicosapentaenoic acid (EPA), Mortierella alpina, solid-state fermentation

\section{INTRODUCTION}

Polyunsaturated fatty acids (PUFAs) such as arachidonic acid (ARA) and eicosapentaenoic acid (EPA) have significant pharmaceutical and nutritional value and great impact on human physiology due to their important roles as structural components of membrane phospholipids and eicosanoid precursors (1-3). Microorganisms, pig liver, adrenal glands and marine fish oil are all sources of PUFAs, e.g. ARA and EPA (4). However, there are some problems with marine resources due to limited fishing quotas and remote geographical locations and the necessity to remove cholesterol, undesirable odours and flavours (5). Some microalgae are suitable sources of EPA, but they require specific conditions for growth, so they are not economically suitable at all times. On the other hand, no plant produces PUFAs longer than $\mathrm{C} 18$, therefore genetic manipulation is necessary to achieve desirable PUFAs $(6,7)$. Thus microorganisms are more preferable to animal-based sources for the production of PUFAs for use as food additives, dietary supplements or feedstock (6).

Production of microbial oil, known as single cell oil (SCO), by Mortierella sp. filamentous fungi, especially M. alpina, has been studied because they are not only a potential source of ARA but can also produce a wide range of PUFAs including ARA and EPA under different culture conditions. Also, similar to other moulds, they could use agricultural and food industrial wastes to manufacture products in solid-state fermentation in the absence or almost complete lack of free water (5). The biosynthesis of fatty acids in most organisms causes the formation of saturated fatty acids of palmitic and stearic acids. These fatty acids can then (by a series of sequential reactions using enzymes, mainly fatty acid elongase) metabolize to a wide range of PUFAs (6).

One of the main parameters that contribute to the production cost of PUFAs is that of the raw material (6). The most cost-effective substrates are the waste materials obtained 
from food industry using solid-state fermentation (SSF) preferably when the product (oil) is intended for human consumption. The ratio of organic carbon to total nitrogen and available trace elements are important for microbial growth and SCO production in SSF (8,9). Date waste and soybean meal are rich in nutrients and could be used as carbon and nitrogen sources for SCO production.

Definite and appropriate designing of fermentation process experiments is important and necessary $(10,11)$. Also, fungal growth in solid-state fermentation is simple and available (12). So far, most of the research on M. alpina has evaluated PUFA production, especially ARA, in submerged fermentation and few were done using SSF. In other studies, PUFA production was performed by culturing M. alpina in SSF on rice and wheat bran, peanut meal and sweet potato residue and their mixtures, press cake (sunflower, soybean, colza and olive), pearl barley, rice without bran, dehulled millet, cracked barley, peanut meal, brewer's spent grain, soybean hall, etc. (13).

The effect of different variables including temperature, time and carbon source concentration on ARA and EPA production is reported in the literature (13-15). However, a comprehensive study considering screening of possible influencing variables on the production of PUFA from date waste in solid-state fermentation has not been conducted. Also, possibility of simultaneous optimum production of these two fatty acids with health benefits has not been reported.

In this research, eleven process variables, namely particle size of the substrate, initial moisture content and $\mathrm{pH}$ of the substrate, carbon to nitrogen ratio of the substrate, supplementations of soybean oil and linseed oil, seed age, incubation temperature and time, heating pretreatment time and supplementation of nitrogen on the fourth day of SSF were investigated with Plackett-Burman design in producing ARA and EPA by M. alpina CBS 528.72 using date waste as carbon source and soybeen meal as nitrogen source, and compared with results of other researchers.

\section{MATERIALS AND METHODS}

\section{Microorganism and substrates}

Mortierella alpina CBS 528.72 was obtained from the Westerdijk Fungal Biodiversity Institute (formerly Centraalbureau voor Schimmelcultures (CBS), Utrecht, the Netherlands). All chemicals used in the experiments were obtained from Carlo Erba Reagents (Val de Reuil, France) unless specified differently. Pentadecaenoic acid used for the gas chromatography (GC) analyses was pur- chased from Merck (Darmstadt, Germany). Malt agar was obtained from Liofilchem (Roseto degli Abruzzi, Italy).

The organism was maintained on malt agar slants, preserved at $4{ }^{\circ} \mathrm{C}$ and subcultured every 2 months (14). Date waste (byproduct of date palm syrup production) was obtained from Khorma Bone Jonoob Company (Bandar Abbas, Iran) and soybean meal from Behpak-Sobhan soy protein company (Behshahr, Iran), linseed oil and soybean oil were purchased from Behshahr Industrial Company (Tehran, Iran). The main chemical compositions of the solid substrates are listed in Table 1.

\section{Mycelial suspension production}

M. alpina CBS 528.72 was incubated at $23^{\circ} \mathrm{C}$ on a medium containing (in $\mathrm{g} / \mathrm{L}$ ): glucose 10 , yeast extract 5 and agar 20, with $\mathrm{pH}=(6.5 \pm 0.1)$, for 96 and $192 \mathrm{~h}$ based on Plackett-Burman experimental design (Table 2 and Table 3). Our previous research (data not shown) did not indicate the necessity of strict $\mathrm{pH}$ control. The $\mathrm{pH}$ was maintained in an interval of $12 \mathrm{~h}$ with 1 $\mathrm{M} \mathrm{NaOH}$ or $1 \mathrm{M} \mathrm{H}_{3} \mathrm{PO}_{4}$ only up to the 5 th day of fermentation. The mycelia were then homogenized with distilled water to produce a suspension of mycelium with an estimated mycelial fragment of (1.5-2) $10^{6}$ cells per $\mathrm{mL}(11,16)$.

\section{Chemical analyses}

Moisture content was adjusted by drying in a vacuum oven until obtaining a constant mass. The substrate $\mathrm{pH}$ was measured with a pH meter (MA235; Mettler Toledo, Greifensee, Switzerland), and then adjusted with $1 \mathrm{M} \mathrm{NaOH}$ or $1 \mathrm{M}$ $\mathrm{HCl}(11,16)$. The percentage of organic carbon was estimated via wet oxidation method using potassium dichromate(VI) and titration with $0.5 \mathrm{M}$ ammonium iron(II) sulfate (17). The percentage of total nitrogen was measured with an automated Kjeldahl apparatus (Kjeltec ${ }^{\mathrm{TM}}$ 8400; FOSS, Hilleroed, Denmark). The oil was extracted from dried substrate using $n$-hexane as solvent and ultrasound device (18). The Soxhlet method was used to measure oil content, while derivatization of fatty acids was done according to Jacobs et al. (19) and Metcalfe et al. (20). ARA and EPA content was determined by gas chromatograph (UNICAM 4600, Cambridge, UK) equipped with capillary BPX70 column (30 m×0.25 mm i.d., $0.25 \mathrm{~mm}$ film thickness; SGE, Melbourne, Australia) and flame ionization detector. Nitrogen was the carrier gas under the pressure of $20 \mathrm{kPa}$. The injector and detector temperatures were maintained at 250 and $300{ }^{\circ} \mathrm{C}$, respectively. The injection volume

Table 1. The main compositions of different solid substrates used for production of ARA and EPA in solid-state fermentation

\begin{tabular}{cccccccccc} 
Substrate & $\begin{array}{c}w \text { (organic } \\
\text { carbon)/\% }\end{array}$ & $\begin{array}{c}w(\text { total } \\
\text { nitrogen)/\% }\end{array}$ & $\mathrm{C} / \mathrm{N}$ & $w$ (moisture)/\% & $w($ oil $) / \%$ & \multicolumn{4}{c}{$w(\mathrm{PUFA}) /(\mathrm{mg} / \mathrm{g})$} \\
\cline { 7 - 10 } & & & & LA & ALA & ARA & EPA \\
Palm date waste & $45.3 \pm 0.6$ & $1.26 \pm 0.04$ & $35.9 \pm 0.8$ & $23.3 \pm 0.1$ & $1.3 \pm 0.3$ & $0.63 \pm 0.06$ & $0.08 \pm 0.03$ & ND & ND \\
Soybean meal & $43.95 \pm 0.05$ & $8.0 \pm 0.2$ & $5.5 \pm 0.2$ & $6.60 \pm 0.04$ & $1.4 \pm 0.2$ & $2.4 \pm 0.2$ & $0.30 \pm 0.02$ & ND & ND \\
Linseed oil & - & - & - & - & - & $116.6 \pm 0.5$ & $383.5 \pm 0.7$ & ND & ND \\
Soybean oil & - & - & - & - & - & $384.0 \pm 0.6$ & $45.1 \pm 0.6$ & ND & ND \\
\hline
\end{tabular}

Mean value \pm standard deviation, $N=3 ; A R A=$ arachidonic acid, $E P A=$ eicosapentaenoic acid, PUFAs=polyunsaturated fatty acids, $L A=$ linoleic acid, ALA $=$ a-linolenic acid, ND=not detected, $-=$ not available 
was $0.2 \mu \mathrm{L}$, with the split ratio of 50:1. Pentadecaenoic acid (15:0) was used as the internal standard.

Table 2. Plackett-Burman design for studying the impact of 11 variables on arachidonic acid (ARA) and eicosapentaenoic acid (EPA) production by Mortierella alpina in solid-state fermentation

\begin{tabular}{lcc} 
Variable & $\begin{array}{c}\text { Low level } \\
(-)\end{array}$ & $\begin{array}{c}\text { High } \\
\text { level }(+)\end{array}$ \\
A: $d$ (substrate particle)/mm & $0.1-0.6$ & $1.2-1.7$ \\
B: $w($ soybean oil)/\% (by mass) & 1 & 10 \\
C: $w($ linseed oil)/\% (by mass) & 1 & 10 \\
D: $w($ substrate initial moisture)/\% & $60-65$ & $70-75$ \\
E: Initial pH of substrate & 6 & 7 \\
F: $t$ (heating pretreatment)/min & 20 & 60 \\
G: Seed age/h & 96 & 192 \\
H: Substrate carbon to nitrogen ratio & 17 & 21 \\
J: Incubation temperature $/{ }^{\circ} \mathrm{C}$ (after 5 days) & 12 & 20 \\
K: $t($ incubation)/day & 4 & 7 \\
L: $w(\mathrm{~N}) / \%$ (by mass) on the fourth day & 0 & 4 \\
\hline
\end{tabular}

\section{Solid-state fermentation}

Based on the desired carbon to nitrogen ratio, a certain amount of date waste and soybean meal was mixed in flasks. Then other process variables, e.g. substrate particle size, moisture content, $\mathrm{pH}$ and the content of soybean oil and linseed oil were adjusted based on the experimental design (Table 2 and Table 3), and then the substrate was mixed. Heat pretreatment was carried out by autoclaving at $121^{\circ} \mathrm{C}$ for 20 and $60 \mathrm{~min}$. After adding $2 \mathrm{~mL}$ of mycelial suspension aged 96 and $192 \mathrm{~h}$, the mixture was inoculated and incubated at $23^{\circ} \mathrm{C}$ for 5 days. On the fourth day of incubation, nitrogen supplement containing potassium nitrate and yeast extract at the ratio 2:1 was added to some flasks according to the experimental design. On the sixth day, the temperature was changed to 20 and $12^{\circ} \mathrm{C}$ for another 4 and 7 days depending on the experimental design. The fermented substrate was dried in a freeze dryer and then ground in a lab mortar $(11,13,14,16)$.

\section{Statistical analysis}

Statistical analysis of the obtained results from both Plackett-Burman design and central composite design (CCD) was performed using MINITAB statistical software v. 14 (21). The data were statistically evaluated using the analysis of variance (ANOVA). Three- and higher-order interactions were eliminated. All data are presented as the mean value \pm standard deviation of two independent experiments on different days. A p-value below 0.05 was considered statistically significant. Table 2 shows factors affecting the production of PUFAs using Plackett-Burman design at two levels. To do so, the Design-Expert v. 8 software $(22)$ was also used $(14,15)$. Range finding was based on literature review and previous research on solid-state production, which will be discussed later (3,8,13-15).

\section{RESULTS AND DISCUSSION}

\section{Composition of solid substrates}

Iran is ranked among the top countries in the world for production of dates as a result of which a large amount of this fruit is converted to agro-industrial wastes. Therefore, this rich source of sugar can be utilized as an available low-cost substrate for cell growth and production (23).

To enhance the growth of Mortierella alpina CBS 528.72 and single cell oil (SCO) production, analysis of substrate's main constituents is important (14). In this study, initial ratio of organic carbon to total nitrogen of date waste was calculated

Table 3. Plackett-Burman design in 12 runs for studying the impact of eleven process variables on arachidonic (ARA) and eicosapentaenoic acid (EPA) production (per $\mathrm{g}$ of dried fermented substrate) in solid-state fermentation

\begin{tabular}{|c|c|c|c|c|c|c|c|c|c|c|c|c|c|c|}
\hline \multirow{2}{*}{ Run no. } & \multicolumn{11}{|c|}{ Variable } & \multirow{2}{*}{$w(\mathrm{ARA}) /(\mathrm{mg} / \mathrm{g})$} & \multirow{2}{*}{$w(\mathrm{EPA}) /(\mathrm{mg} / \mathrm{g})$} & \multirow{2}{*}{$w($ oil $) / \%$} \\
\hline & $A$ & B & C & $\mathrm{D}$ & $E$ & $\mathrm{~F}$ & G & $\mathrm{H}$ & $\mathrm{J}$ & $\mathrm{K}$ & $\mathrm{L}$ & & & \\
\hline 1 & + & + & - & + & + & + & - & - & - & + & - & $(2.95 \pm 0.08)^{\mathrm{e}}$ & $(0.07 \pm 0.02)^{b}$ & $17.5 \pm 0.8$ \\
\hline 2 & - & + & + & - & + & + & + & - & - & - & + & $(0.73 \pm 0.01)^{\mathrm{b}}$ & $(0.04 \pm 0.01)^{\mathrm{a}}$ & $23.0 \pm 1$ \\
\hline 3 & + & - & + & + & - & + & + & + & - & - & - & $(2.5 \pm 0.11)^{d}$ & $(0.06 \pm 0.02)^{b}$ & $15.99 \pm 0.02$ \\
\hline 4 & - & + & - & + & + & - & + & + & + & - & - & $(0.19 \pm 0.01)^{\mathrm{a}}$ & $(0.04 \pm 0.01)^{\mathrm{a}}$ & $15.0 \pm 0.4$ \\
\hline 5 & - & - & + & - & + & + & - & + & + & + & - & $(0.31 \pm 0.04)^{\mathrm{a}}$ & $(0.04 \pm 0.01)^{\mathrm{a}}$ & $14.7 \pm 1.1$ \\
\hline 6 & - & - & - & + & - & + & + & - & + & + & + & $(0.59 \pm 0.06)^{b}$ & $(0.02 \pm 0.01)^{\mathrm{a}}$ & $6.5 \pm 1.2$ \\
\hline 7 & + & - & - & - & + & - & + & + & - & + & + & $(0.68 \pm 0.06)^{b}$ & $(0.06 \pm 0.01)^{\mathrm{b}}$ & $7.4 \pm 0.7$ \\
\hline 8 & + & + & - & - & - & + & - & + & + & - & + & $(1.39 \pm 0.04)^{c}$ & $(0.01 \pm 0.01)^{\mathrm{a}}$ & $17.7 \pm 0.9$ \\
\hline 9 & + & + & + & - & - & - & + & - & + & + & - & $(1.24 \pm 0.01)^{c}$ & $(0.06 \pm 0.01)^{\mathrm{b}}$ & $23.3 \pm 0.9$ \\
\hline 10 & - & + & + & + & - & - & - & + & - & + & + & $(4.38 \pm 0.40)^{f}$ & $(0.87 \pm 0.09)^{c}$ & $25.5 \pm 0.5$ \\
\hline 11 & + & - & + & + & + & - & - & - & + & - & + & $(4.7 \pm 0.47)^{g}$ & $(1.86 \pm 0.08)^{d}$ & $18.8 \pm 1.0$ \\
\hline $\begin{array}{l}\text { Coeff. } \\
\text { ARA* }^{*}\end{array}$ & $\begin{array}{l}\infty \\
\stackrel{n}{+} \\
+\end{array}$ & 苕 & $\begin{array}{l}\bullet \\
+ \\
+\end{array}$ & $\begin{array}{l}\infty \\
\infty \\
+\end{array}$ & 岪 & 崩 & $\begin{array}{l}\infty \\
0 \\
i\end{array}$ & w & 岂 & 岂 & $\stackrel{\stackrel{+}{+}}{+}$ & - & - & \\
\hline $\begin{array}{l}\text { Coeff. } \\
\text { EPA* }^{*}\end{array}$ & w & w & $\stackrel{m}{+}$ & 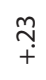 & w & $\underset{1}{\gtrless}$ & $\bar{i}$ & జ & w & w & $\underset{+}{+}$ & - & - & \\
\hline
\end{tabular}

*Coefficients of factors influencing ARA and EPA production; A-L=variables the same as in Table 2, NSE=not significant effect. Values with the same letter in each column are not significantly different 
to be $35.9 \pm 0.8$ (Table 1). Koike et al. (24) reported that carbon to nitrogen ratio of 7-15 was suitable for lipid production by M. alpina, which increased in range of 15-32. Generally, the best carbon to nitrogen ratio has been reported to be from 15:1 to $20: 1(13,24)$. Therefore, soybean meal was used as a nitrogen source and carbon to nitrogen ratio of the substrate was adjusted at two levels $(17,23)$.

Soybean meal is suitable for producing some PUFAs like ARA and is economically justifiable (14). The oils extracted from date waste and soybean meal, soybean oil and linseed oil used as supplements did not contain ARA and EPA; therefore, production of the mentioned fatty acids could be related to the role of independent variables and their levels. In fact, date waste and soybean meal are also oil supplements which contain PUFAs including linoleic acid and a-linolenic acid (ALA), which stimulate the production of other PUFAs such as ARA and EPA in different species of Mortierella, e.g. M. alpina (25).

\section{Influence of process parameters on ARA and EPA production}

According to the results of Plackett-Burman design for ARA and EPA production (Table 3 ) based on the analysis of variance, the Pareto charts of variables (Fig. 1) were drawn. The coefficients of significant factors affecting each of them show that positive coefficients indicate direct relation between the variable and the considered response and negative coefficients indicate an inverse relationship between them (Table 3). Positive sign of the coefficient means that by increasing the level of a variable from low to high leads to increasing the dependent variable or response (in this study ARA and EPA production). Coefficient with a negative sign means that by changing the level of variable from low to high, the response decreases.

\section{Particle size of the substrate}

In this study, the coarse substrate particles have been shown to have a significant positive impact on the production of ARA compared with fine particles. However, the particle size was not an effective and significant factor in EPA production. Ghobadi et al. (18) showed that coarser substrate particles increase the production of ARA; thus, they introduced it as a significant effective factor.

In general, coarse substrate particles prevent aggregation of particles in aerobic fungi during fermentation and lead to more free air flow and better penetration into mycelium substrate, which improves the production of a product that requires further oxygen (26). Therefore, the size of substrate particles is important variable when SSF depends strongly on oxygen availability (18). Key point in SSF is that particle size of substrate has a critical and narrow range because it influences the mass and heat transfer as well as the surface to volume ratio of particle (which is important for availability and consumption of substrate). In fact, decreasing the particle size causes an increase in the surface to volume ratio, which a)

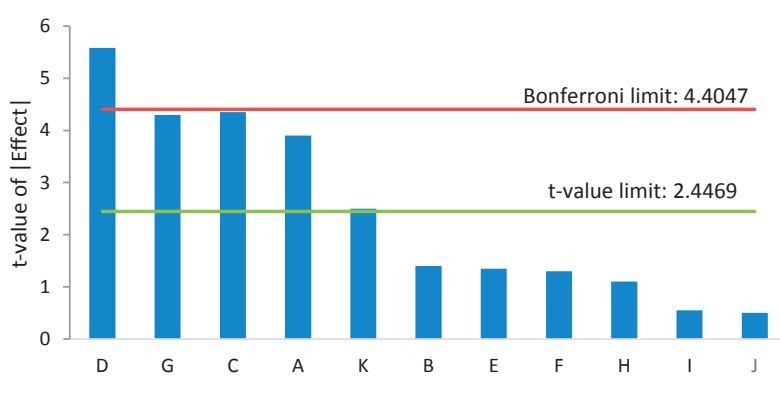

b)

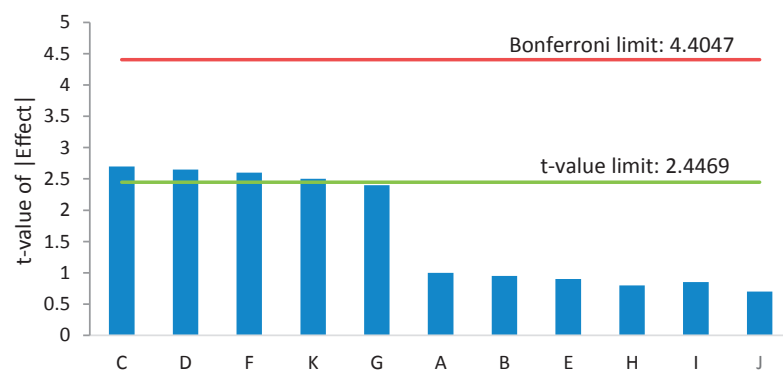

Fig. 1. Pareto chart of influence of process variables on: a) arachidonic acid (ARA) and b) eicosapentaenoic acid (EPA) production ( $A=$ particle size of substrate, $B=$ soybean oil supplement, $C=$ linseed oil supplement, $\mathrm{D}=$ substrate initial moisture content, $\mathrm{E}=$-initial $\mathrm{pH}$ of substrate, $\mathrm{F}=$ heating pretreatment time, $\mathrm{G}=$ seed age, $\mathrm{H}=$ carbon to nitrogen ratio, I=incubation temperature after 5 days, J=incubation time, $\mathrm{K}=\mathrm{ni}-$ trogen supplementation on the fourth day)

enables the contact between the particle and the enzymes produced by the microorganism. Further decrease of particle size leads to poor heat and mass transfer due to reduced inter-particle space. It has been shown that SSF with aeration increased the production of arachidonic acids, EPA, and total PUFAs (16). It can be interpreted from the results that both particle sizes used in this study were suitable for air transfer in culture and EPA production, while the fungus required further oxygen for production of ARA. PUFAs are produced through enzymatic unsaturation with oxygen; thus, adequate oxygenation is the key factor in achieving high PUFA content in mycelial cells (27).

\section{Seed age}

Seed age (the incubation period of mycelia prior to inoculation) is an effective and significantly negative factor in production of ARA and EPA by M. alpina. In other words, compared to the mycelia aged for $192 \mathrm{~h}$, inoculation of young mycelia (aged for $96 \mathrm{~h}$ ) increased the production of desired fatty acids. This was consistent with the research of Fakas et al. (28) who studied $M$. isabellina on solid culture medium of pear pomace and revealed the relationship between the unsaturation of fatty acids and mycelial age. They found that PUFAs were particularly high in young mycelia and their amount was reduced by ageing. PUFAs were better biosynthesized in fast-growing young mycelia, while their synthesis was significantly reduced in old mycelia. 
Changes in fatty acid profiles with mycelium ageing are due to the changes in their biosynthesis process, particularly changes in the rate of fatty acid unsaturation.

\section{Heating pretreatment time}

The results showed a significantly inverse relationship between the duration of heating pretreatment of the substrate and EPA production, probably due to excessive hydrolysis or loss of some nutrients in the substrate and interference in the activity of unsaturated enzymes of $M$. alpina. Furthermore, no significant impact was observed on ARA production, probably because the changes in substrate did not affect the activity of the aforementioned enzymes. However, the solid substrate has to be treated to release the nutrients. Ghobadi et al. (18) hydrolyzed the substrate at $121^{\circ} \mathrm{C}$ for $30 \mathrm{~min}$. Therefore, in order to save energy, 20-30 min of autoclaving is recommended for this fungus (13).

\section{Nitrogen supplementation}

Adding nitrogen on the fourth day was one of the significant factors for producing ARA and EPA; in other words, adding $4 \%$ (by mass) supplement to the substrate increased the amount of ARA and EPA. These results are in agreement with those of Jang and Yang (16), who supplemented solid substrates fermented by M. alpina with nitrogen sources, including yeast extract and nitrate, and realized that the produced PUFAs depended on the amount of nitrogen supplement. Supplementing with 3.75 to $7.5 \%$ nitrogen source on the fourth growth day was suitable for producing $\omega-3$ PUFAs, especially EPA (11). This finding is in agreement with the report of Ben-Amotz et al. (29) who indicated that high nitrogen concentrations could strengthen EPA production. Also Jang and Yang (16) found that culturing rice bran on solid substrate with nitrogen supplement resulted in better growth and adding nitrogen source on the fourth day in a column reactor increased EPA production.

Although lipid accumulation is affected by high ratio of carbon to nitrogen (30), further addition of nitrogen source (a combination of yeast extract and $\mathrm{KNO}_{3}$ ) to the substrate on the fourth day of fermentation might enhance microbial growth and thus increase PUFA production (16).

\section{Oil supplementation}

Results of this research showed that the addition of linseed oil to the substrate was an effective and significant factor with a positive effect on the production of ARA and EPA by M. alpina, while the addition of soybean oil did not have a significant effect on the amount of produced ARA and EPA. In other words, incorporation of $10 \%$ (by mass) linseed oil to the substrate increased the production of ARA and EPA. The results were consistent with reports by some researchers, where with the addition of $10 \%$ (by mass) linseed oil to the solid substrate the production of PUFAs increased in most of the investigated species of Mortierella $(11,16,19,31)$.
Results of Jang et al. (32) showed that cellular mass increased with the increase of concentration of soybean oil and became stable at $1 \%$. The amount of ARA and desaturation decreased with the increase of soybean concentration (31). Jang et al. (32) showed that the addition of $1 \%$ soybean oil and $1 \%$ linseed oil to rice bran increased the efficiency of total PUFAs, linoleic acid, ARA and EPA. This difference probably resulted from the difference in the type of substrate and conditions of fermentation $(11,13)$.

Therefore, it could be concluded that adding $10 \%$ (by mass) linseed oil caused greater increase of ARA and EPA than adding $10 \%$ soybean oil. In other words, adding linseed oil had greater effect on desaturation of the oil produced by M. alpina than adding soybean oil to the substrate, which showed that, by culturing this fungus, linseed oil could be metabolized more effectively and that it had a positive effect on the production of PUFAs. Due to the rich content of oleic, linoleic and a-linolenic acids and use of precursors by Mortierella fungus, they could be desirable for producing PUFAs. The mentioned findings confirm that M. alpina is capable of using lipids added to the medium for producing PUFAs, which is done by desaturation and elongation of fatty acids (33).

\section{Substrate initial moisture content}

Initial moisture content of the substrate is very important for SSF (13). The results show that at the initial moisture of the substrate of $75 \%$, the production of ARA and EPA by M. alpina increased. Maximum and minimum moisture content in SSF depends on substrate characteristics, especially its water activity, because above a critical point the free water particles may appear, filling the inter-particle space between substrate particles and acting as a barrier for mass and heat transfer in SSF.

It had a significantly positive effect and was consistent with the results reported by other researchers on production of ARA in rice bran by M. alpina. Jang and Yang (16) found that optimum initial moisture for total PUFA, linoleic acid and ARA production by M. alpina in rice bran was about $57 \%$, while maximum initial moisture for the production of ALA and EPA was $64 \%$. Initial amount of moisture was reported to be about 70 to $75 \%$ for producing $\omega-6$ PUFAs and moisture of 60 to $65 \%$ was suitable for producing $\omega-3$ PUFAs $(11,16)$. In contrast, in this work, $75 \%$ moisture was shown to be suitable for EPA production. Moreover, in reports of Zhang and $\mathrm{Hu}$ (34) on soybean hull and Economou et al. (35) on sweet sorghum using $M$. isabellina, initial moisture of about 75 and $92 \%$ respectively was reported as the reason for increased production of unicellular oil. This difference could be attributed to the discrepancy in substrate type and its moisture absorption because the amount of moisture is a function of absorbability of the substrate. Zadražil and Brunnert (36) showed that low moisture decreased solubility of nutrients and substrate inflation. Also, high moisture caused loss of porosity, induced sticky substrate particles and decreased exchange of oxygen gas. Thus, very high and very low moisture are not suitable for metabolite production (11). 


\section{Incubation temperature}

In this research, temperature had no significant effect on the production of ARA and EPA. However, other researchers have reported temperature as one of the functional factors in producing biomass, oil and fatty acids, especially by M. alpina $(11,16,18)$. In other words, temperature results of this research did not imply inconsistency with results of other researchers because temperature might not be introduced as a significantly functional factor due to the selection of the studied temperature range and differences in other conditions of fermentation.

Nevertheless, in studies by other researchers $(11,37)$, the temperature required for biomass production is usually reported higher than the temperature needed for production of PUFAs. Mortierella species such as M. alpina have shown the best growth at $23-25^{\circ} \mathrm{C}$ and the largest amount of PUFA was produced at $16-20^{\circ} \mathrm{C}$. Also, some evidence indicates that the desaturation of ARA to EPA by $n-3$ desaturase is stimulated by growth of Mortierella at low temperature (6).

\section{Incubation time}

As with any other biotechnological fermentation, the optimum incubation time is important for metabolite production. M. alpina species produced the largest amount of PUFAs during 10 to 15 days. The important point was that excessive increase of fermentation time decreased economic conservation of the product produced by the microorganism. Considering this factor, optimum incubation time should be selected so that maximum efficiency is achieved during the minimum possible time $(13,37)$.

Although a significantly negative effect of time on ARA production was reported Ghobadi et al. (18); in this report, it was not introduced among significant factors for production of ARA and EPA. This difference could be attributed to different species of fungus, types of substrate and selected time intervals. Probably, if different periods of time for their production were studied, it would have been reported as a significant factor because the two selected incubation times in this research were suitable for SCO production.

Fakas et al. (28) found that the amount of oil in pear pomace fermented by cultivation of $M$. isabellina fungus on the 9 th day after insemination was about $12 \%$ of the maximum value, which decreased after 12 days. Furthermore, Jang and Yang (16) reported that production of PUFAs by M. alpina on rice bran solid substrate for 12 days was stable and unchanged. The results showed a constant microbial growth in solid substrate during 12 days, and PUFA content in mycelium of fungus was accumulated without any decrease in efficiency.

Fakas et al. (28) studied PUFA production by M. isabellina in SSF of pear pomace and reported that production yield reached a maximum in young mycelia and then by further prolonging the fermentation time (up to 1 day), it decreased in old fungi. In another study, Jang and Yang (16) reported that production of PUFAs by M. alpina SSF was stable for 12 days of incubation without a decrease in production yield. The reason for such difference between SSF reports may strongly depend on the applied microorganism and substrate. Carbon source in fruit waste is simpler than lignocellulose ligands of bran, so change in its content (and resulting changes in C/N ratio) may directly influence PUFA production. In some cases a slow and constant fungal growth and PUFA production were reported in SSF (11).

\section{Carbon to nitrogen ratio of substrate}

Some researchers have reported that carbon to nitrogen ratio of solid substrate is crucial for mould growth and lipid production (10,32). In this study, C/N ratio was not a significant factor for ARA and EPA production, probably due to the selected range of variables. In other words, both selected levels were in the optimum range for producing PUFAs. Other researchers $(13,24)$ observed $\mathrm{C} / \mathrm{N}$ ratio of the substrate in the range of $15-20$, which is desirable for $M$. alpina growth and lipid production. $\mathrm{C} / \mathrm{N}$ ratio of between 14.5 and 18.5 was suitable for EPA production and 19.8 and 21 was suitable for ARA and total PUFA production (9).

Also at different $\mathrm{C} / \mathrm{N}$ ratio, the amount of other ingredients of date waste also varies. In fact, increasing the carbon source is a consequence of some other effective metal ions in date extract, as a complex medium, such as iron, potassium, magnesium, manganese, sodium, phosphorus and copper (data not shown). These metal ions can act as inhibitors of biomass and PUFA production directly or indirectly. Most growth inhibition compounds found in date extract are acids, phenol and quinine compounds (23).

\section{Initial $\mathrm{pH}$ of substrate}

The initial pH of the substrate is an important factor for fungal growth and has low impact on fatty acid type (13). In this study, selection of $\mathrm{pH}=6$ and 7 , which are the optimum values for production of PUFAs in SSF, was not recognized as a significant factor for ARA and EPA production. Jang et al. (9) also found that optimum pH for production of PUFAs in SSF by M. alpina is 6 to 7 , and PUFA production decreased at a $\mathrm{pH}$ greater than 8 or lower than 5 . Other researchers have also reported that slightly acidic to neutral $\mathrm{pH}$, i.e. from 6 to 7 , is optimal for production of ARA, EPA and PUFAs by Mortierella in SSF $(5,16,38)$.

\section{CCD design}

The results for ARA and EPA production by M. alpina during SSF of date waste for 6 days according to CCD (Table 4) are presented in Fig. 2 and Fig. 3. In all trials, non-significant parameters of Placket-Burman design were fixed at the corresponding acceptable levels and CCD was designed based on three variables, linseed oil, seed age and mass fraction of nitrogen supplement, which were more significant in fermentation of both fatty acids. The variables were fixed at their most suitable levels (for ARA the fixed variables were $D+G-C+A+L+$ and for EPA C+D+F-G-L+, based on Table 2 coding). 
Table 4. Central composite design for studying the impact of three selected variables and their levels (based on $a:-1.34,-1,0,+1$ and +1.34) on arachidonic acid (ARA) and eicosapentaenoic acid (EPA) production by Mortierella alpina in solid-state fermentation

\begin{tabular}{cccccc} 
No & $w(\mathrm{LSO}) / \%$ & $\begin{array}{c}\text { Seed } \\
\text { age/h }\end{array}$ & $w(\mathrm{~N}) / \%^{*}$ & $\begin{array}{c}w(\mathrm{ARA}) / \\
(\mathrm{mg} / \mathrm{g})\end{array}$ & $\begin{array}{c}w(\mathrm{EPA}) / \\
(\mathrm{mg} / \mathrm{g})\end{array}$ \\
\hline 1 & 12 & 100 & 5.00 & $5.75^{\mathrm{e}}$ & $0.18^{\mathrm{b}}$ \\
2 & 8 & 100 & 2.50 & $3.51^{\mathrm{c}}$ & $0.05^{\mathrm{a}}$ \\
3 & 10 & 115 & 3.75 & $6.07^{\mathrm{f}}$ & $0.08^{\mathrm{a}}$ \\
4 & 12 & 70 & 5.00 & $8.65^{\mathrm{i}}$ & $4.53^{\mathrm{g}}$ \\
5 & 10 & 85 & 1.25 & $9.01^{\mathrm{j}}$ & $3.71^{\mathrm{f}}$ \\
6 & 8 & 100 & 5.00 & $8.62^{\mathrm{i}}$ & $3.43^{\mathrm{e}}$ \\
7 & 10 & 55 & 3.75 & $6.02^{\mathrm{f}}$ & $2.51^{\mathrm{d}}$ \\
8 & 10 & 85 & 6.25 & $6.18^{\mathrm{f}}$ & $3.64^{\mathrm{f}}$ \\
9 & 10 & 85 & 3.75 & $4.32^{\mathrm{d}}$ & $0.06^{\mathrm{a}}$ \\
10 & 12 & 70 & 2.50 & $5.51^{\mathrm{e}}$ & $0.07^{\mathrm{a}}$ \\
11 & 10 & 85 & 3.75 & $4.37^{\mathrm{d}}$ & $0.07^{\mathrm{a}}$ \\
12 & 8 & 70 & 5.00 & $6.05^{\mathrm{f}}$ & $0.16^{\mathrm{b}}$ \\
13 & 12 & 100 & 2.50 & $7.34^{\mathrm{h}}$ & $0.83^{\mathrm{c}}$ \\
14 & 10 & 85 & 3.75 & $4.30^{\mathrm{d}}$ & $0.80^{\mathrm{c}}$ \\
15 & 10 & 85 & 3.75 & $3.05^{\mathrm{b}}$ & $0.05^{\mathrm{a}}$ \\
16 & 6 & 85 & 3.75 & $6.65^{\mathrm{g}}$ & $0.78^{\mathrm{c}}$ \\
17 & 8 & 70 & 2.50 & $6.16^{\mathrm{f}}$ & $0.75^{\mathrm{c}}$ \\
18 & 10 & 85 & 3.75 & $3.44^{\mathrm{c}}$ & $0.62^{\mathrm{c}}$ \\
19 & 10 & 85 & 3.75 & $2.52^{\mathrm{a}}$ & $2.51^{\mathrm{d}}$ \\
20 & 14 & 85 & 3.75 & $3.56^{\mathrm{c}}$ & $3.43^{\mathrm{e}}$ \\
\hline
\end{tabular}

*Nitrogen supplementation on the fourth day, LSO=linseed oil supplement. Values with the same letter in each column are not significantly different

Fig. 2 and Fig. 3 show the response surface plots of the ARA and EPA produced by M. alpina on date waste in SSF as a function of linseed oil, seed age and mass fraction of nitrogen supplement. According to the plots, by increasing the mass fraction of nitrogen source, production of ARA decreased, while linseed oil and seed age were at their optimum levels to improve production. CCD was focused on significant variables only.

According to the results obtained from data analysis, the highest produced mass fraction of ARA was $9.01 \mathrm{mg} / \mathrm{g}$ (trial number 5) when inoculation was conducted by young ( 85 h) seeds on date waste containing linseed oil 10 and nitrogen $1.25 \%$ (by mass) ( $\mathrm{p} \leq 0.05)$. The highest production of EPA of $4.53 \mathrm{mg} / \mathrm{g}$ (Table 4) was obtained in trial number 4 , where date waste contained linseed oil 12 and nitrogen $5 \%$ (by mass) when using young seeds (aged $70 \mathrm{~h}$ ) ( $\mathrm{p} \leq 0.05)$. It is worth mentioning that the obtained optimized levels of each CCD variable in fatty acid production are consistent with the results obtained using Plackett-Burman design. Between two examined levels of linseed oil in Plackett-Burman design (1 and 10), the higher was the better. Thus, in CCD, 5 levels were selected around $10(6,8,10,12$ and 14) and again the highest was the best. In the case of seed age, between 2 levels (96 and 192) of Plackett-Burman design the lower was the better. Thus, in CCD, 5 levels were selected around 96 (55, 70, 85, 100 and 115) and again the lowest was the best (14). Also, Plackett-Burman design indicated that with supplementation of a)

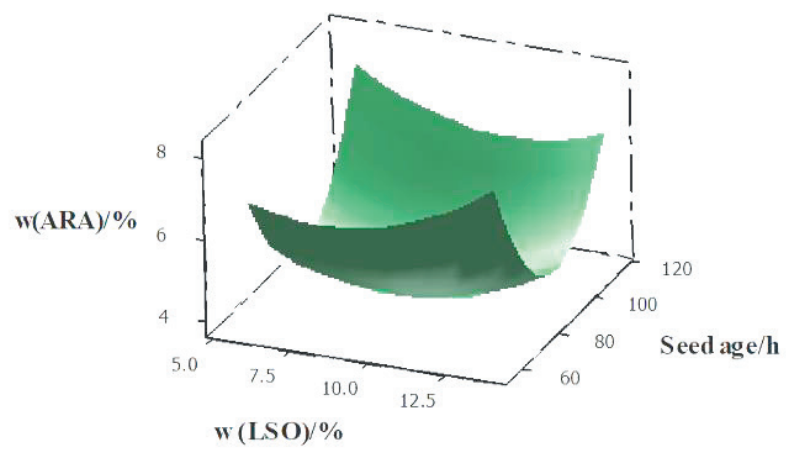

b)

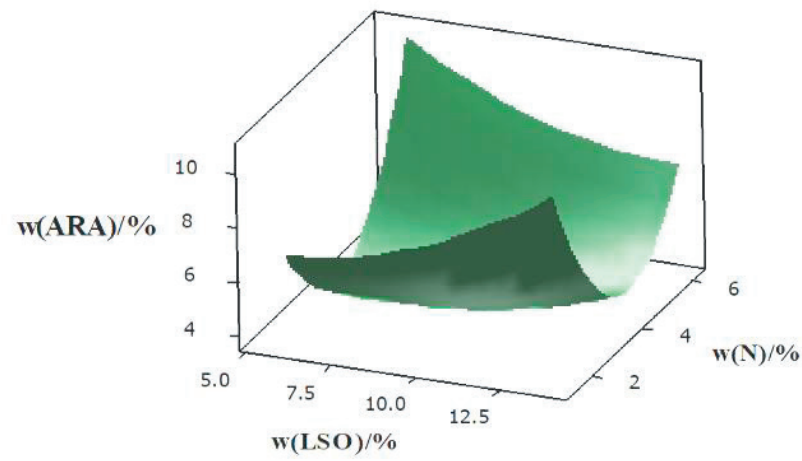

c)

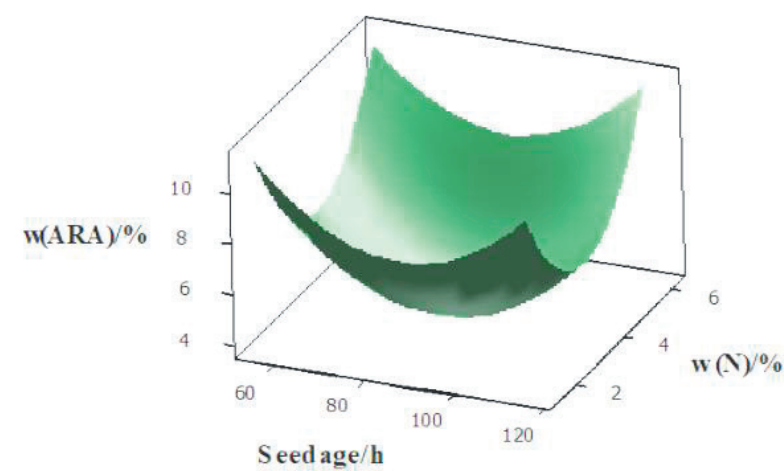

Fig. 2. Impact of main variables (seed age, nitrogen and linseed oil supplementation) and their interaction effects on arachidonic acid (ARA) production by Mortierella alpina in solid-state fermentation: a) ARA vs. seed age and linseed oil supplementation, b) ARA vs. nitrogen and linseed oil supplementation, and c) ARA vs. nitrogen supplementation and seed age

nitrogen ( $4 \%$ ) the production of both fatty acids increased, so CCD levels were adjusted around 4 (1.25, 2.50, 3.75, 5.00 and 6.25). ARA production was induced in the presence of $1.25 \%$ nitrogen, but EPA production still increased with the increase of nitrogen to $6.25 \%$. Greater seed age led to low production of both fatty acids, as shown in Fig. 2-Fig. 4.

Fakas et al. (28) compared PUFA production by young and aged mycelia and showed that young are rich in polar lipids (containing almost $40 \%$, by mass, PUFAs), which decreased to less than $30 \%$ by mass in aged mycelia, while neutral lipid 
a)

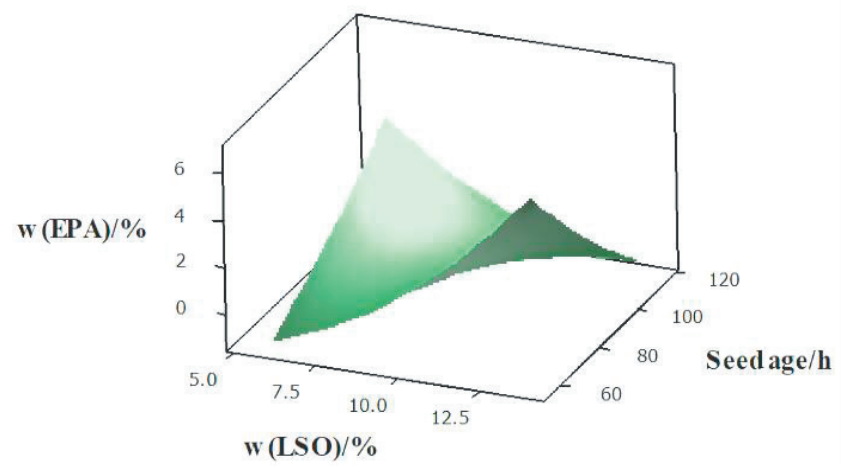

b)

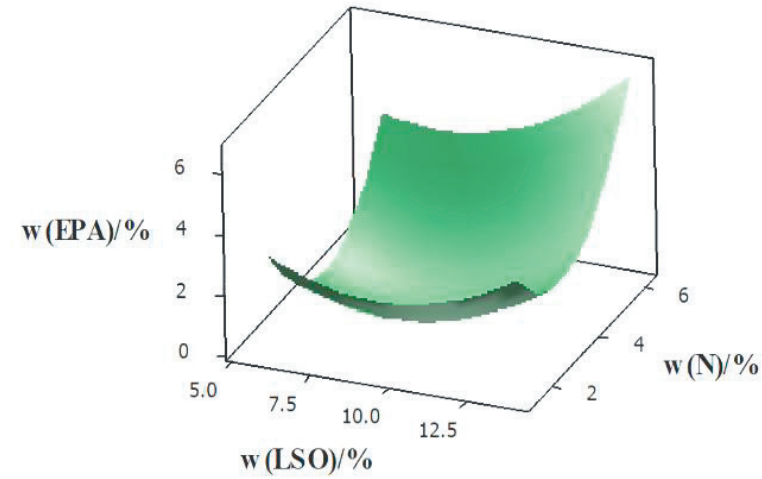

c)

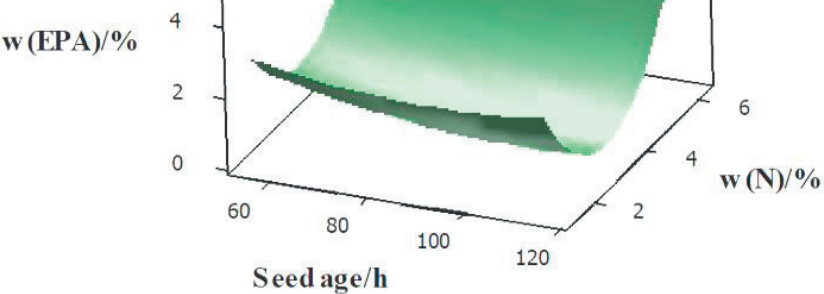

Fig. 3. Impact of main variables (seed age, nitrogen and linseed oil supplementation) and their interaction effects on eicosapentaenoic acid (EPA) production by Mortierella alpina in solid-state fermentation: a) EPA vs. seed age and linseed oil supplementation, b) EPA vs. nitrogen and linseed oil supplementation, and c) EPA vs. nitrogen supplementation and seed age

content increased in aged mycelia. They also report slight fluctuation of PUFA content in neutral lipids with age and finally indicate that PUFA biosynthesis is favoured in young, fast growing mycelia, while it decreases significantly in aged mycelia.

The coefficient of regression $\left(R^{2}\right)$ for fatty acid production during 6 days of fermentation was 0.93 . Analysis of variance of the stepwise regression showed a first order polynomial model that fits the data well. Also, in the residual plots a trend in the distribution of the residuals around the zero line (means the goodness of fit) was not observed. The value of $\mathrm{R}^{2}$ showed good agreement between experimental and predicted values. The F ratio for the lack-of-fit of the model for fatty acid production during 6 days of fermentation was not significant $(p>0.05)$. The polynomial mathematical model is as follows:

$$
Y(\text { fatty a cid })=1.22+0.655 w(N)+0.346 w(\text { linseed }
$$$$
\text { oil) }+0.00440 t \text { (mycelial incubation) }
$$

\section{Validation of data}

Table 4 shows CCD used to study the impact of three selected variables and their levels (based on $a=-1.34,-1,0$, +1 and +1.34 ) on ARA and EPA production by M. alpina in solid-state fermentation. The results indicated that optimum conditions for ARA production may be achieved by supplementation of linseed oil and nitrogen source at 14.0 and $1.25 \%$ (by mass) respectively and seed aged for $55 \mathrm{~h}$.

The production of ARA and EPA under the optimized conditions (with the addition of optimum amounts of linseed oil and nitrogen at optimum seed age) was examined during 6 days of fermentation. The results showed that the yield of ARA and EPA after 6 days of fermentation reached (14.37 \pm 0.06$)$ and $(11.35 \pm 0.09) \mathrm{mg} / \mathrm{g}$, respectively. It is worth mentioning that a control sample (date waste) was tested in order to validate the optimized conditions. The control sample was inoculated with a similar amount of fungi and almost $0.1 \mathrm{mg} / \mathrm{g}$ of ARA and EPA were produced after 6 days of fermentation.

The comparison of the obtained results with other reports showed that there is a variety of reports on PUFA production on different solid substrates. Total final lipid mass fraction reached $47.9 \mathrm{mg}$ from $1 \mathrm{~g}$ of soybean hull, where fatty acid content consisted of $30.0 \%$ of total lipids, and 80.4 $\%$ of total fatty acids were C16 and C18 (34). It can be concluded that $11.28 \mathrm{mg}$ of each C16 and C18 are produced from $1 \mathrm{~g}$ of soybean hull. Also, in another report (18), arachidonic acid production by M. alpina CBS 754.68 in SSF reached $1.14 \mathrm{mg} / \mathrm{g}$. M. isabellina produced the maximum GLA mass fraction of $2.9 \mathrm{mg}$ per $\mathrm{g}$ of dry biomass in SSF (28). In SSF on rice bran M. alpina produced (in $\mathrm{mg} / \mathrm{g}$ ): total PUFAs 127, EPA 12, AA 6, arachidonic acid 6, ALA 5 and linoleic acid 117 after 12 days of incubation $(11,16)$. When Microsphaeropsis sp. was cultured in pretreated cellulose containing wheat straw and wheat bran, SCO reached $74 \mathrm{mg} / \mathrm{g}$ and the SCO content of the dry fermented mass was $10.2 \%$ (7). M. alpina and $M$. basiparvispora produced 6.4 and $5.8 \mathrm{mg}$ of EPA, respectively, per $\mathrm{g}$ of sunflower press cake (19). Also in a semi-solid-state fermentation of Mortierella isabellina on sweet sorghum, oil production reached $11 \mathrm{~g}$ per $100 \mathrm{~g}$ of dry mass of substrate (35). To date, the maximum yield of PUFAs in SSF has been reported to be $(103 \pm 5.2) \mathrm{mg} / \mathrm{g}$ using M. alpina ATCC 32222 on rice bran, where ARA and EPA reached (33.35 \pm 2.13$)$ and (12.77 \pm 1.61$)$, respectively (13). 
a)

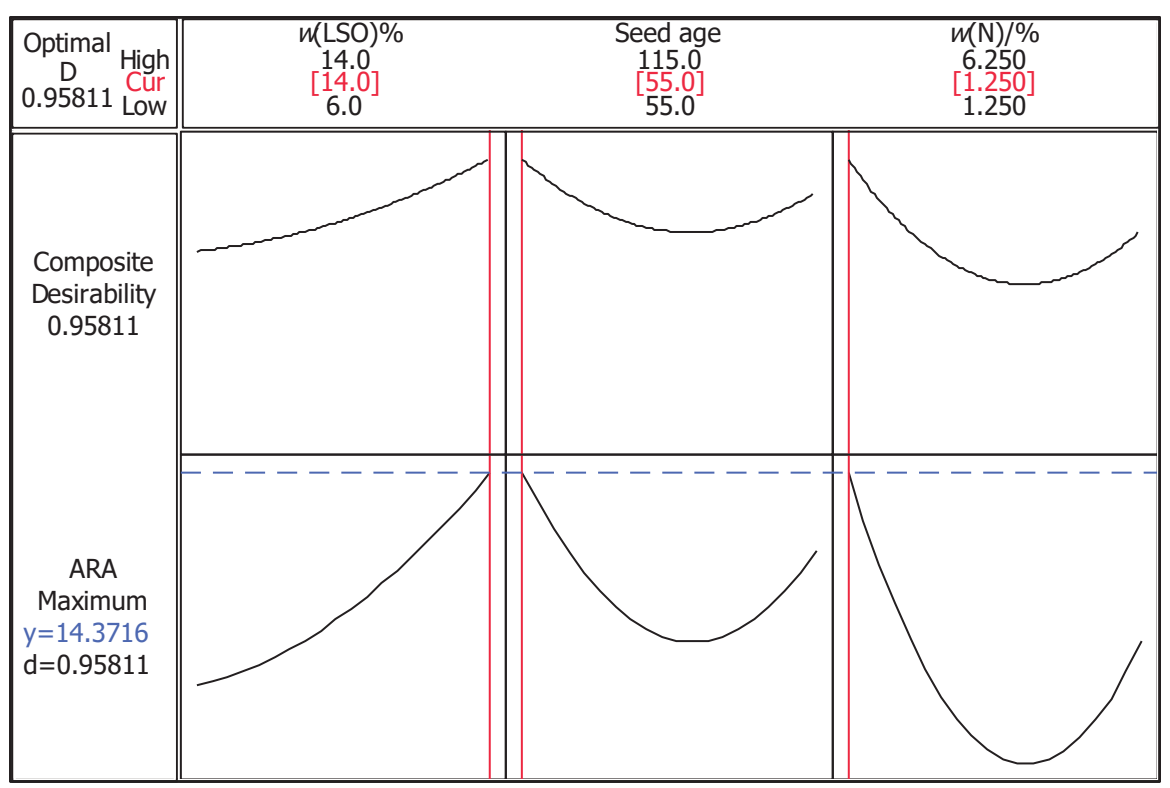

b)

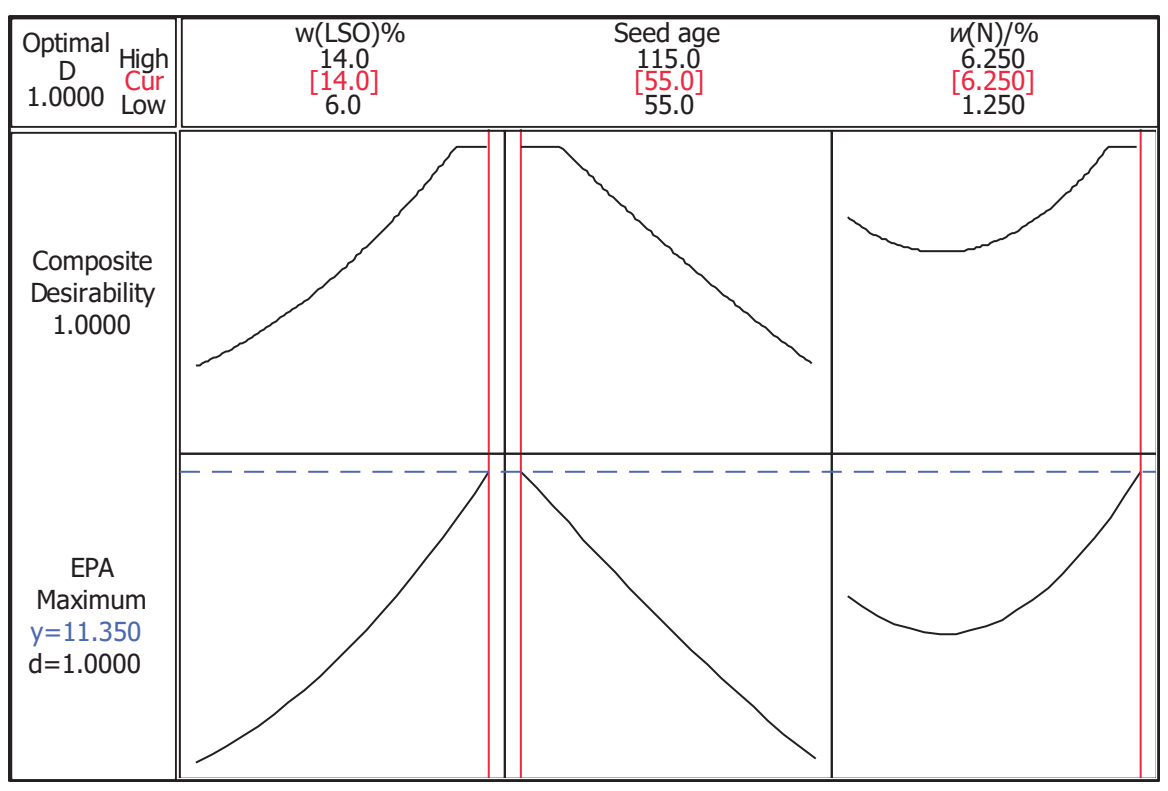

Fig. 4. Influence of optimum conditions and levels of main variables (seed age, nitrogen and linseed oil supplementation) on: a) arachidonic acid (ARA), and b) eicosapentaenoic acid (EPA) production by Mortierella alpina in solid-state fermetation

\section{CONCLUSIONS}

In this research, substrate initial moisture and the addition of linseed oil and nitrogen on the fourth day had a positive effect, while seed age had a negative effect on the production of arachidonic (ARA) and eicosapentaenoic acids (EPA). Particle size of the substrate had a significantly positive effect on ARA production by Mortierella alpina. Duration of heating pretreatment had a negative effect only on EPA production. In the selected range of variables, substrate initial moisture content of $70-75 \%$, addition of $10 \%$ (by mass) of linseed oil and
$4 \%$ (by mass) nitrogen, particle size of the substrate of 1.2$1.7 \mathrm{~mm}$ and seed age of $96 \mathrm{~h}$ had high impact on the increase of ARA yield. Also, the addition of $10 \%$ (by mass) linseed oil and $4 \%$ (by mass) nitrogen supplement, seed age of $96 \mathrm{~h}$, substrate initial moisture content of $70-75 \%$ and 20 min of heating pretreatment had a high impact on the increased production of EPA. The highest values of produced ARA and EPA in Plackett-Burman design using M. alpina were 4.66 and 1.86 mg per $g$ of dry fermented substrate, respectively (experiment 11). When conditions were optimized with response surface 
methodology, ARA and EPA production reached (14.37 \pm 0.06$)$ and $(11.35 \pm 0.09) \mathrm{mg} / \mathrm{g}$, respectively, after 6 days of fermentation.

However, for optimum production of EPA, supplementation of nitrogen source needs to be $6.25 \%$ (by mass), while other conditions are similar. Therefore, it can be concluded that if the aim is simultaneous production of both fatty acids, a two-phase fermentation is required. All conditions are similar for both fatty acids, while a change in nitrogen supplementation from 1.25 to 6.25 leads to shift of production from ARA to EPA. It can be concluded that high levels of $\mathrm{N}$ supplementation supported the EPA production. This is most likely due to the role of components of this nitrogen source. It is obvious that developing the industry of converting date waste into worthy materials provides a great help for solving the problem of fatty acid deficiency.

\section{ACKNOWLEDGEMENTS}

Hereby we would like to thank the authorities of Tarbiat Modares University for providing laboratory facilities, the authorities of National Nutrition and Food Technology Research Institute for financial support and for providing the main part of laboratory facilities, the authorities of Islamic Azad University, Science and Research Branch, and laboratory complex of the related unit for supplying a part of required materials and laboratory equipment and others who supported us in this research.

\section{REFERENCES}

1. Mirbagheri M, Nahvi I, Emamzade R. Reduction of chemical and biological oxygen demands from oil wastes via oleaginous fungi: An attempt to convert food by products to essential fatty acids. Iran J Biotechnol. 2015;13(2):25-30. https://doi.org/10.15171/JJB.1026

2. Sakuradani E, Shimizu S. Single cell oil production by Mortierella alpina. J Biotechnol. 2009;144(1):31-6. https://doi.org/10.1016/j.jbiotec.2009.04.012

3. Wu ST, Yu ST, Lin LP. Effect of culture conditions on decosahexaenoic acid production by Schizochytrium sp. S31. Process Biochem. 2005;40(9):3103-8. https://doi.org/10.1016/j.procbio.2005.03.007

4. Cheng MH, Walker TH, Hulbert GJ, Raman DR. Fungal production of eicosapentaenoic and arachidonic acids from industrial waste streams and crude soybean oil. Bioresour Technol. 1999;67(2):101-10. https://doi.org/10.1016/S0960-8524(98)00113-8

5. Bellou S, Moustogianni A, Makri A, Aggelis G. Lipids containing polyunsaturated fatty acids synthesized by Zygomycetes grown on glycerol. Appl Biochem Biotechnol. 2012;166(1):146-58. https://doi.org/10.1007/s12010-011-9411-z

6. Ratledge C. Fatty acid biosynthesis in microorganisms being used for single cell oil production. Biochimie.
2004:86(11):807-15.

https://doi.org/10.1016/j.biochi.2004.09.017

7. Peng X, Chen H. Single cell oil production in solid-state fermentation by Microsphaeropsis sp. from steam-exploded wheat straw mixed with wheat bran. Bioresour Technol. 2008;99(9):3885-9. https://doi.org/10.1016/j.biortech.2007.08.015

8. Šajbidor J, Dobroñová S, Čertík M. Arachidonic acid production by Mortierella sp. S-17: Influence of C/N ratio. Biotechnol Lett. 1990;12(6):455-6.

https://doi.org/10.1007/BF01024404

9. Jang HD, Lin YY, Yang SS. Polyunsaturated fatty acid production with Mortierella alpina by solid substrate fermentation. Bot Bull Acad Sin. 2000;41:41-8.

10. Vasheghani Farahani E, Khosravi-Darani K, Shojaosadati SA. Application of the Taguchi design for production of poly( $\beta$-hydroxybutyrate) by Ralstonia eutropha. Iran J Chem Chem Eng. 2004;23(1):131-6.

11. Khosravi Darani K, Zoghi A, Alavi SA, Fatemi SSA. Application of Plackett Burman design for citric acid production from pretreated and untreated wheat straw. Iran J Chem Chem Eng. 2008;27(1):91-104.

12. Panesar PS, Kaur R, Singla G, Sangwan RS. Bio-processing of agro-industrial wastes for production of food-grade enzymes: Progress and prospects. Appl Food Biotechnol. 2016;3(4):208-27.

https://doi.org/10.22037/afb.v3i4.13458

13. Asadi SZ, Khosravi-Darani K, Nikoopour H, Bakhoda H. Evaluation of the effect of process variables on the fatty acid profile of single cell oil produced by Mortierella using solid-state fermentation. Crit Rev Biotechnol. 2015;35(1):94-102. https://doi.org/10.3109/07388551.2013.804805

14. Malaiwong N, Yongmanitchai W, Chonudomkul D. Optimization of arachidonic acid production from Mortierella alpina PRAO7-10 by response surface methodology. Agr Natural Res. 2016;50(3):162-72. https://doi.org/10.1016/j.anres.2016.06.003

15. Rocky-Salimi K, Hamidi-Esfahani Z, Abbasi S. Statistical optimization of arachidonic acid production by Mortierella alpina CBS 754.68 in submerged fermentation. Iran J Biotechnol. 2011;9(2):87-93.

16. Jang HD, Yang SS. Polyunsaturated fatty acids production with a solid-state column reactor. Bioresour Technol. 2008;99(14):6181-9. https://doi.org/10.1016/j.biortech.2007.12.024

17. Nelson DW, Sommers LE. Total carbon organic carbon and organic matter. In: Page AL, Miller RH, Keeney DR, editors. Methods of soil analysis: Part 2. Chemical and microbiological properties. Madison, WI, USA: ASA SSSA;1982. pp. 54260.

18. Ghobadi Z, Hamidi-Esfahani Z, Azizi MH. Determination of effective variables on arachidonic acid production by Mortierella alpina CBS 754.68 in solid-state fermentation us- 
ing Plackett-Burman screening design. World Acad Sci Eng Technol. 2011;5(9):800-2.

19. Jacobs A, Botha A, Reddy JK, Van Zyl WH. Sunflower press cake as a substrate for eicosapentaenoic acid production by representatives of the genus Mortierella. Bioresources. 2010;5(2):1232-43.

20. Metcalfe LD, Schmitz AA, Pelka JR. Rapid preparation of fatty acid esters from lipids for gas chromatographic analysis. Anal Chem. 1966;38(3):514-5. https://doi.org/10.1021/ac60235a044

21. MINITAB, v. 14. State College, PA, USA: Minitab, Inc.; 2017. Available from: https://softadvice.informer.com/Minitab_12_Free_Download.html.

22. Design-Expert, v. 8, Minneapolis, MN, USA: Stat-Ease, Inc; 2017. Available from: https://en.freedownloadmanager. org/Windows-PC/Design-Expert.html.

23. Khosravi-Darani K, Reyhani FS, Nejad BN, Farhadi GBN. Bench scale production of xanthan from date extract by Xanthomonas campestris in submerged fermentation using central composite design. Afr J Biotechnol. 2011;10(62):13520-7. https://doi.org/10.5897/AJB11.018.

24. Koike Y, Cai HJ, Higashiyama K, Fujikawa S, Park EY. Effect of consumed carbon to nitrogen ratio on mycelial morphology and arachidonic acid production in cultures of Mortierella alpina. J Biosci Bioeng. 2001;9(14):382-9. https://doi.org/10.1016/S1389-1723(01)80156-0

25. Weber RWS, Tribe HT. Oil as a substrate for Mortierella species. Mycologist. 2003;17(3):134-9. https://doi.org/10.1017/S0269915X03002039

26. Pandey A, Soccol CR, Mitchell D. New developments in solid state fermentation: I-bioprocesses and products. Process Biochem. 2000;35(10):1153-69. https://doi.org/10.1016/S0032-9592(00)00152-7

27. Higashiyama K, Fujikawa S, Park EY, Shimizu S. Production of arachidonic acid by Mortierella fungi. Biotechnol Bioprocess Eng. 2002;7(5):252-62. https://doi.org/10.1007/BF02932833

28. Fakas S, Makri A, Mavromati M, Tselepi M, Aggelis G. Fatty acid composition in lipid fractions lengthwise the mycelium of Mortierella isabellina and lipid production by solid state fermentation. Bioresour Technol. 2009;100(23):6118-20. https://doi.org/10.1016/j.biortech.2009.06.015

29. Ben-Amotz A, Tornabene TG, Thomas WH. Chemical profile of selected species of microalgae with emphasis on lipids.
J Phycol. 1985;21(1):72-81.

https://doi.org/10.1111/j.0022-3646.1985.00072.x

30. Dyal SD, Bouzidi L, Narine SS. Maximizing the production of $\mathrm{Y}$-linolenic acid in Mortierella ramanniana var. ramanniana as a function of $\mathrm{pH}$, temperature and carbon source, nitrogen source, metal ions and oil supplementation. Food Res Int. 2005;38(7):815-29.

https://doi.org/10.1016/j.foodres.2005.04.002

31. Jacobs A, Botha A, Van Zyl WH. The production of eicosapentaenoic acid by representatives of the genus Mortierella grown on brewers' spent grain. Biologia. 2009;64(5):8716. https://doi.org/10.2478/s11756-009-0152-1

32. Jang HD, Lin YY, Yang SS. Effect of culture media and conditions on polyunsaturated fatty acids production by Mortierella alpina. Bioresour Technol. 2005;96(15):1633-44. https://doi.org/10.1016/j.biortech.2004.12.027

33. Certik M, Sakuradani E, Shimizu S. Desaturase-defective fungal mutants: Useful tools for the regulation and overproduction of polyunsaturated fatty acids. Trends Biotechnol. 1998;16(12):500-5. https://doi.org/10.1016/S0167-7799(98)01244-X

34. Zhang J, Hu B. Solid-state fermentation of Mortierella isabellina for lipid production from soybean hull. Appl Biochem Biotechnol. 2012;166(4):1034-46.

https://doi.org/10.1007/s12010-011-9491-9

35. Economou CN, Makri A, Aggelis G, Pavlou S, Vayenas DV. Semi-solid state fermentation of sweet sorghum for the bio technological production of single cell oil. Bioresour Technol. 2010;101(4):1385-8.

https://doi.org/10.1016/j.biortech.2009.09.028

36. Zadražil F, Brunnert H. Investigation of physical parameters important for the solid state fermentation of straw by white rot fungi. Eur J Appl Microbiol Biotechnol. 1981;11(3):183-8. https://doi.org/10.1007/BF00511259

37. Dyal SD, Narine SS. Implications for the use of Mortierella fungi in the industrial production of essential fatty acids. Food Res Int. 2005;38(4):445-67. https://doi.org/10.1016/j.foodres.2004.11.002

38. Bajpai PK, Bajpai P, Ward OP. Production of arachidonic acid by Mortierella alpina ATCC 32222. J Ind Microbiol. 1991;8(3):179-85.

https://doi.org/10.1007/BF01575851 